\title{
PENGARUH SELF-CONTROL, SELF-ESTEEM, PARENTING STYLE, DAN LONELINESS TERHADAP ADIKSI SMARTPHONE SISWA SMA
}

\author{
Kodariyah Nurhayat \\ Universitas Indraprasta PGRI Jakarta
}

\begin{abstract}
Abstrak
Adiksi internet merupakan suatu keadaan dimana seseorang tidak dapat mengontrol dirinya untuk terus mengakses internet. Ada beberapa faktor yang menyebabkan terjadinya adiksi internet, yaitu self-control, loneliness dan parenting style. Tujuan penelitian ini adalah ingin mengetahui seberapa besar pengaruh Selfcontrol sebagai mediator antara self-esteem, permissive parenting style dan loneliness terhadap adiksi internet menggunakan smartphone. Populasi dalam penelitian ini adalah siswa SMA X BSD. Sampel dalam penelitian ini berjumlah 103 diolah dan disajikan dengan menggunakan table Morgan. Pengumpulan data menggunakan skala self-esteem, parenting permissive style dan loneliness. Analisis data diolah menggunakan analisis multiregresi. Temuan penelitian menunjukkan bahwa terdapat pengaruh antara selfesteem, permissive parenting style dan loneliness terhadap adiksi internet menggunakan smartphone dengan self-control sebagai mediator di SMA ISLAM X. Artinya tingkat adiksi internet melalui smartphone siswa dipengaruhi oleh self-control, self-esteem, permissive parenting style dan loneliness. .
\end{abstract}

Kata Kunci: Adiksi internet, self-control, Self-Esteem, Parenting Permissive Style, dan Loneliness. .

\begin{abstract}
Internet addiction is an incapability of avoiding the habituae of using gadget, where the users are absorbing into their favorite application and or activity. There are factors caused the internet addiction; lots of spare time which lead to boringness, search for sensation and self esteem. However, according to some psychological, literature self control, loneliness and parenting style are also the cause of the addiction. The objective of this research is to investigate the effect of self-control as a mediator among self-esteem, permissive parenting style, and loneliness towards the internet addiction, among students in SMA X. This research used product moment analysis for validity test and alpha cronbach on reliability test.
\end{abstract}

Keywords: Internet addiction, Self-Control, Self-Esteem, Parenting Permissive Style dan loneliness.

\section{PENDAHULUAN}

Anak-anak merupakan calon pemimpin bangsa dan garda depan dalam pembangunan bangsa. Sekarang anakanak begitu dimanjakan oleh teknologi informasi dan komunikasi (TIK). Internet sudah menjadi kebutuhan pokok anak-anak saat ini khususnya sebagai pelajar. Tugas-tugas disekolah menuntut mereka untuk mencari banyak referensi di internet. Hal itu adalah salah satu dampak positif internet. Namun, ibarat pisau bermata dua. Internet juga memberikan dampak negatif bila disalah pergunakan oleh anak. Kebebasan mengakses situs internet bisa menjerumuskan anak itu sendiri bila tanpa pengawasan dari orang tua. Pendapat tersebut dikuatkan oleh laporan analisis mintel yang dipublish The Sun, kamis (3/11/2011) yang menyatakan bahwa sekitar 970.000 anakanak secara regular masuk ke jejaring social media melalui berbagai perangkat gadged seperti PC,laptop, hingga smartphone.(Oase, 2012)

Penetrasi gadget yang kian massif dikalangan masyarakat dewasa tak luput pula terjadi pada kalangan anak-anak disekitar kita. Khususnya masyarakat Indonesia yang bahkan menjadi salah satu pengguna internet dengan prangkat ponsel terbesar. Hal ini tentu kian mengkhawatirkan, dikarenakan gadget akhirnya menggantikan peran-peran sosial yang seharusnya dilakukan oleh anak-anak seperti interaksi dengan orang tua, teman, lingkungan, dan interaksi dengan kreativitas didunia nyata. Gadget pun seakan menjadi hantu paling dahsyat menggempur mentalitas anak, dimana tak sedikit prangkat gadget yang terhubung dengan dunia internet, dimana internet telah mahfum untuk kita ketahui bersama, ia menjadi jembatan mereka dengan dunia kekerasan, bulliying, dan juga pornografi. Hal ini sejalan dengan pendapat Elly risman pakar parenting yang menyatakan bahwa kerusakan itu bermula dari genggaman melalui gadget dan internet. (Oase, 2012)

Maraknya media sosial yang bisa diakses melalui handphone atau laptop atau gadget lainnya menimbulkan dampak pada anak berupa kurang bisanya berinteraksi dengan teman sebaya diluar rumah. Selain itu anak-anak bisa berteman dengan siapapun yang memiliki akun di media social tersebut. Kekhawatiran akan pengaruh buruk lingkungan menjadi sebab orang tua bersikap keras 
terhadap penggunaan internet pada anak. Game online adalah game yang bisa dimainkan oleh dua orang atau lebih yang komputernya terhubung dijaringan internet. Mereka bisa betah berjam-jam didepan layar computer untuk bermain games. Hal ini tentu memberikan dampak negatif. Anak-anak jadi kurang berkomunikasi dengan lingkungan sekitarnya.. Selain itu bila sudah kecanduan game online mereka jadi melupakan kewajibannya untuk belajar dirumah. (Chusna,2017)

Cyber addiction atau kecanduan game, internet, gadget dan sarana elektronik lainnya yang berhubungan dengan dunia maya menjadi hal yang mengkhawatirkan beberapa tahun belakangan ini, kecanduan cyber ini tidak hanya terjadi pada orang dewasa tetapi juga pada anak dan remaja. Kecanduan cyber membuat seseorang cenderung anti sosial, sulit berkonsentrasi, dan dampak buruk lainnya. Gangguan lainya adalah gangguan otak karena paparan berulang zat atau pengulangan aktifitas tertentu yang dapat meningkatkan pelepasan neurotransmitter dopamine pada sirkuit dopaminergic mesokortikolimbik sehingga menimbulkan efek reward. Pelepasan dopamine secara abnormal berulang mendorong terjadinya neuroadaptasi yang mengubah fungsi sirkuit tersebut yang termanifestasi dalam bentuk perilaku kompulsif yang khas pada kondisi adiksi. Nyeri kronis dan stress diketahui merupakan factor resiko dalam kerentanan akan terjadinya adiksi (Tanamal,2016)

Berpisah sehari saja dari gadget yang berbasis fasilitas internet seperti smartphone misalnya akan menimbulkan perasaan gugup, panic, stress, bahkan depresi bagi mereka yang sudah kecanduan gadget. Demikian hasil riset yang dipublish International Center for Media \& the Public Agenda (ICMPA) di University of Maryland awal tahun 2011. Dalam studinya, ICMPA mengajak sekitar 1.000 mahasiswa dari 10 negara di lima benua berbeda untuk tidak menggunakan internet selama 24 jam. Setelah melewati satu hari tanpa akses internet melalui ponsel, blackberry, laptop, mp3 player dan gadget lainnya. Para mahasiswa itu kemudian merekam pengalaman mereka.

Berdasarkan seluruh respon yang diperoleh, ICMPA menyimpulkan bahwa individu yang berusia dibawah 25 tahun, tidak peduli dari mana mereka berasal dan apapun agamanya, menjadi tidak "berfungsi" secara optimal tanpa menggunakan gadget. Demikian seperti yang dilansir Celluler News, Sabtu (9/4/2011).

Seorang mahasiswa asal Amerika Serikat mengungkapkan, "Saya merasa gatal, seperti seorang pecandu, karena tidak bisa menggunakan ponsel saya." Golitsinski, 2011 menambahkan bahwa gadget ternyata bukan hanya sekedar perangkat untuk berkomunikasi para mahasiswa. Mereka mengatakan, betapa gadget telah membentuk pikiran orang lain tentang mereka dan cara pikir mereka terhadap diri mereka sendiri. "Disamping itu banyak dari responden yang mengatakan bahwa mahasiswa diseluruh dunia menjadikan gadget, terutama ponsel, bisa memberikan rasa nyaman secara mental maupun fisik. Faktanya, ponsel kini menjadi semacam selimut keamanan bagi generasi modern"

Berdasarkan riset yang dilakukan oleh Novanty,dkk, 2019) tentang gambaran kecanduan internet pada siswa SMA. Dari riset ini dapat disimpulkan bahwa sebagian remaja sekarang sudah ketergantungan bahkan masuk dalam tahap kecanduan gadget yang dioperasikan melalui internet. Kemajuan dan inovasi teknologi ternyata menyebabkan remaja diseluruh dunia tergantung pada berbagai perangkat pintar. "Berpisah" sehari saja dari gadget akan menimbulkan perasaan gugup, panic, stress hingga depresi.

International Center for Media \& the Public Agenda (ICMPA) di University of Maryland. Dalam studinya, ICMPA mengajak sekira 1.000 mahasiswa dari 10 negara di lima benua berbeda untuk tidak menggunakan gadget apapun selama 24 jam. Berdasarkan survey ini, sekitar 970.000 anak-anak secara regular masuk ke jejaring social facebook melalui berbagai perangkat seperti PC, laptop, hingga smartphone. Sebanyak $46 \%$ anak-anak menyatakan, mereka menggunakan situs itu hanya sekali. Hanya satu dari 20 anak menyatakan mereka pernah log on. Laporan ini juga menunjukan, pengguna facebook seharihari paling banyak dilakukan anak-anak perempuan usia 10-12 tahun. Sekitar 54\% dari mereka umumnya log on minimal sekali dalam sehari.

Jejaring social berikutnya yang paling popular bagi anak-anak adalah twitter, whats app, line, BBM, snapchat, instagram, dll. Hal ini belum termasuk aplikasi internet lain seperti youtube, google, dan aplikasi games. Analis Mintel menyebutkan, dorongan teman sebaya adalah motivasi utama anak-anak menggunakan jaringan social. Hampir dua pertiga dari anak berusia 7-12 tahun menggunakan jaringan social karena teman mereka menggunakannya.

Penulis laporan Lifestyle Anak-anak dari Mintel, Ina Mitskavets, menyoroti betapa populernya situs ini. "Anak-anak sekarang mengenal semua aspek internet. Dengan hampir satu juta anak usia 7-12 tahun diyakini telah menggunakan facebook”. Para peneliti di Eropa juga mengungkapkan, anak-anak menghabiskan sekitar 3-5 jam sehari, baik disekolah, maupun di rumah, dan diakhir pekan dengan menonton TV dan mengakses internet untuk social media mereka.

Penelitian lain tentang adiksi internet melalui berbagai perangkat gadget menyatakan bahwa bisa berakibat fatal salah satunya adalah gangguan mental. Padahal, beberapa tahun sebelumnya, para ilmuan psikologi tidak sependapat memasukan gejala adiksi internet sebagai gangguan mental atau kejiwaan 
(Oase,2012). Hasil penelitian tersebut mengungkapkan bahwa otak remaja yang adiksi internet melalui berbagai perangkat gadget memiliki 'materi putih' yang abnormal. Materi putih adalah lapisan yang memisahkan dan mengelilingi kabel syaraf antara sel-sel syaraf. "Daerah materi putih yang ditujukan dalam penelitian ini telah diketahui terlibat dalam perilaku kecanduan dan kompulsif", (Wallis, 2012). Lanjut Wallis, yang meyakini, rusaknya selubung putih tersebut menggangu komunikasi otak, sehingga seseorang yang mengalaminya akan berfikir bahwa perilakunya berharga dan harus diulang lagi dan lagi dan seterusnya. "Kerusakan selubung putih ini, saya yakin menjadi kunci atas berbagai jenis kecanduan pada manusia, khususnya kecanduan terhadap teknologi, internet, gadget, dan lainnya."

Kemudian yang disediakan oleh internet menjadikan internet sebagai bagian dari kehidupan seharihari. Bagi mayoritas individu, internet merupakan alat informasi yang luar biasa dan alat yang dapat membuka kesempatan untuk menghubungkan diri secara social serta dapat membawa perubahan kesejahteraan hidup menjadi lebih baik. Hal tersebut membuat individu sulit untuk melepaskan diri dari keterikatannya dengan internet dan membawa kecenderungan kearah kecanduan, APA (dalam Young dan Abreu, 2011)

Pertumbuhan jumlah pengguna internet yang cepat dan banyaknya keinginan untuk dapat menggunakan internet dimanapun dan kapanpun ini memunculkan fasilitas baru yang memudahkan seseorang dalam menggunakan internet yaitu smartphone, smartphone merupakan sebuah perangkat komunikasi canggih yang memiliki jaringan internet didalamnya sehingga memudahkan seseorang dalam menjalankan keseharian atau bisa juga disebut sebagai computer kecil yang mempunyai kemampuan sebuah telepon. Survey yang dilakukan oleh MarkPlus Insight (2011) membuktikan peningkatan jumlah pengguna internet di Indonesia, dari sekitar 240 juta jiwa penduduk Indonesia, pengguna internet pada tahun 2011 mencapai 55 juta orang, dan 50\% atau sekitar 29 juta jiwa pengguna internet di Indonesia menggunakan fasilitas smartphone untuk mengaksesnya (Karimudin, dalam daily social,2011). Smartphone memudahkan seseorang dalam menjalankan aktifitasnya terutama dalam berkomunikasi dan mengakses internet, ini yang menyebabkan seseorang bukan hanya sekedar adiksi internet saja namun menjadi adiksi smartphone.

Menurut Taylor (dalam Richard,J. 2009) dengan smartphone, seseorang akan selalu diperingatkan oleh email, telephone, sms, dan tanda jejaring sosial dan teman, keluarga, dan rekan kerja ini juga dapat menyebabkan seseorang menjadi adiksi terhadap smartphone. Sudah menjadi fakta bahwa ketika seseorang sudah terkena adiksi, smartphone menjadi hal pertama yang dilihat dipagi hari, dan smartphone juga menjadi hal terakhir yang dilihat sebelum tidur.

Ketika seseorang terkena adiksi smartphone, ada kebutuhan atau kebiasaan untuk mengambil smartphone mereka dan memeriksanya saat bergetar atau berdering, bahkan terkadang bila smartphone hanya diam seseorang bisa mengambilnya hanya untuk memastikan tidak ada yang berubah pada layar smartphone mereka. Banyak pengguna smartphone Blackberry atau android rutin merujuk keperangkat mereka sebagai "crackberry", yang mengungkapkan fakta bahwa penggunaan smartphone dapat menjadi hal yang sangat adiktif (Langfitt, 2005). Ini bisa terlihat dalam salah satu website "Crackberry.com" yang merupakan sebuah forum online untuk seorang "pelaku" untuk mengakui mereka "adiksi", dimana ribuan pengguna mendiskusikan pengguna adiksi smartphone mereka. Dalam Crackberry.com ini banyak self-report yang membuktikan bahwa sejumlah besar pengguna smartphone mungkin akan mengalami ketergantungan yang tidak diinginkan pada smartphone yang mereka gunakan.

Adiksi smartphone terbukti memberi beberapa kerugian terhadap orang-orang yang terlalu sering menggunakan smartphone. Seperti pada pejalan kaki yang selalu focus melihat smartphone saat melintas dijalan., tanpa memeriksa lalu lintas memungkinkan mereka akan tertabrak mobil, atau seseorang menggunakan smartphone saat mengemudi dapat menyebabkan kecelakaan mobil, dan anak-anak sekolah dasar sangat rentan bagi mereka untuk adiksi game smartphone serta video game internet yang membuat mereka tidak bisa berkonsentrasi dikelas, dan meningkatnya biaya rata-rata penggunaan ponsel atau smartphone (kwon,M.dkk.2013). Cooper (2002) juga mengatakan bahwa kerugian dari adiksi yaitu dapat menimbulkan perilaku seperti kurang tidur, mudah mengalami kelelahan, performa kerja menurun, kurangnya focus, serta menjadi pribadi yang cepat marah ketika tidak sedang berinteraksi dengan hal yang disenanginya.

Beberapa perilaku yang terlihat dari siswa yang menggunakan smartphone yaitu, menggunakan smartphone disemua kegiatan, saat melihat smartphone fokus mereka terhadap dunia nyata teralihkan dan muncul perilaku mengacuhkan orang lain yang ada disekitar mereka. Beberapa orang menyatakan, menggunakan smartphone dapat memberikan dampak lupa waktu dan mengalihkan focus terhadap kegiatan yang sedang dilakukan. Bahkan ketika keluarga sedang makan bersama disebuah restoran, ayah, ibu dan anak-anaknya sibuk untuk memperhatikan smartphone mereka masing-masing, sehingga komunikasi antar keluarga pun berkurang sama halnya dengan yang dikemukakan oleh Coper bahwa melihat layar secara konstan membuat individu menjauh 
dari orang lain, individu tidak berinteraksi dengan dunia nyata atau menghadapi masalah yang ada didepan mata

Dampak negative yang paling sering dialami ketika menggunakan smartphone adalah $31 \%$ menyatakan mereka menjadi ketergantungan dengan kata lain mereka selalu ingin menggunakan dan memegang smartphone mereka setidaknya hanya mengecek recent update aplikasi chating, 25\& menyatakan dengan menggunakan smartphone sering lupa waktu sehingga kegiatan mereka sering terlupakan, 19\% menyatakan acuh terhadap lingkungan sekitar mereka dan 19\% menyatakan menghabiskan uang mereka untuk mengaktifkan paket smartphone.(Oase,2012)

Bianchi and Philips (dalam Philips,J.2006) menemukan bahwa orang yang mengalami adiksi smartphone cenderung menyembunyikan suatu hal yang nyata dari keluarga dan teman, menghadapi krisis keuangan, merasa sibuk, cemas, depresi ketika keluar dari jangkauan smartphone untuk beberapa waktu, terus gagal untuk mengontrol dan mengurangi penggunaaan smartphone dan menggunakan smartphone untuk lari dari masalah atau keadaan darurat.

Studi yang dilakukan Bindwell (2007) mengungkapkan bahwa penggunaan smartphone menunjukan banyak pola perilaku yang sama dengan kebiasaan dari pengguna narkoba. Seperti perasaan untuk merasa lebih baik dengan menggunakan smartphone, menggunakannya lebih sering untuk mendapatkan perasaan yang sama (membangun toleransi), dan akan mengalami penarikan ketika kehilangan akses untuk menggunakan smartphone. Banyak pengguna smartphone telah mengatakan bahwa mereka menjadi sangat cemas ketika smartphone mereka mati atau saat smartphone mereka tertinggal dirumah. Nam (2013) menyatakan bahwa seseorang dinyatakan adiksi smartphone jika menghabiskan lebih dari tujuh jam dalam sehari memainkan smartphone dan mengalami gangguan kecemasan, sulit tidur dan depresi saat tidak berhubungan dengan smartphone mereka. Sedangkan menurut DSM IV adiksi merupakan penggunaan suatu benda yang mengarah pada penurunan klinis yang signifikan atau adanya tekanan pada diri sendiri yang terjadi ketika seseorang menggunakannya dalam waktu 12 bulan/ 1 tahun.

Dalam jurnal "Cellular phone: The Solution or pollution" dikatakan bahwa psikiater percaya bahwa adiksi smartphone akan menjadi salah satu adiksi non-obat terbesar yang menggangu kehidupan sosial. Banyak ilmuan percaya bahwa gangguan pada system otak ataupun psikis seperti atensi yang berkurang atau pun hilang dan terganggunya system kognitif bagi penggunanya (Goel, A,dkk, 2012).

Adiksi smartphone ini sulit untuk dihilangkan, bahkan dalam sehari saja pengguna salah satu brand smartphone di Indonesia bisa melihat gadget lebih dari ratusan kali. Seseorang yang terkena adiksi smartphone biasanya secara tidak sadar akan mengecek smartphone mereka dalam waktu begitu singkat atau sedikitnya memeriksa smartphone mereka sebanyak 34 kali dalam sehari (www.goodpaste.com). Bahkan dalam journal Personal and Ubiquotous Computing yang merilis penelitian tentang kebiasaan secara kompulsif memeriksa smartphone dan menyatakan bahwa seseorang secara berulang-ulang bisa mengecek smartphone paling tidak selama 30 detik sehari.

Dalam sebuah survey yang dilakukan oleh Stanford University pada tahun 2010, ditemukan bahwa siswa yang menggunakan 200 iPhone, bisa menjadi adiktif baik bagi yang baru menggunakan smartphone tersebut ataupun yang sudah lama menggunakannya. Banyak pengguna mengandalkan pada iPhone sebagai bagian dari gaya hidup mereka, $10 \%$ dari mereka menyatakan adiksi iPhone, 34\% menyatakan hamper mengalami adiksi, dan $6 \%$ menyatakan mereka tidak mengalami adiksi. Kemudian ditemukan, $75 \%$ mengaku tidur disamping iPhone mereka, dan 69\% melaporkan bahwa mereka lebih memungkinkan untuk melupakan dompet mereka dari pada iPhone mereka. Hal ini menunjukan kekuatan adiktif dari smartphone (Hope,D. 2010).

Adiksi smartphone merupakan kecanduan kondisi terikat pada suatu kebiasaan dan tidak mampu lepas dari kebiasaan itu, individu kurang mampu mengontrol dirinya sendiri untuk melakukan kegiatan yang disenanginya. Menurut Leung (dalm Casey,B.M, 2012) ada beberapa faktor yang menyebabkan terjadinya adiksi smartphone, yaitu adanya kesenggangan waktu sehingga bosan, mencari sensasi dan self esteem. Namun menurut literatur psikologi lainnya self-control, loneliness dan parenting style juga menjadi predictor seseorang mengalami adiksi smartphone pada murid-murid di china (Casey,B.M, 2012)

Mengenai kontrol diri (self-control), seseorang pecandu akan menjadi tidak mampu mengontrol dirinya untuk melakukan kegiatan yang ia senangi sehingga mengabaikan hal lainnya. Kontrol diri seseorang bisa terbentuk karena adanya aturan-aturan atau hukum yang mengikat diri agar tingkah laku yang diwujudkan bisa dikendalikan. Kegagalan dalam mengendalikan diri tersebut pada akhirnya akan membawa dampak yang negatif khususnya dalam bentuk kecanduan. Banyaknya kemampuan yang dimiliki oleh internet membuat seseorang dapat dengan mudah memenuhi kebutuhannya hanya dengan "berselancar" di internet sehingga terjadilah adiksi.

Hal ini didukung dengan teori kebutuhan maslow bahwa didalam setiap individu ada dorongan untuk memenuhi kebutuhan pada tiap tingkatan. Kebutuhan yang dapat diperoleh melalui internet seperti kebutuhan rasa 
aman (membangun privacy individual/ kebebasan diri) serta kebutuhan akan kasih sayang ( menginginkan sebuah persahabatan dan menjadi bagian dari suatu kelompok). Individu yang tahu bahwa kebutuhannya dapat terpenuhi melalui internet dan memiliki self-control yang rendah berpotensi mengalami kecanduan karena menjadi tidak mampu untuk mengatur dirinya.

Faktor lain yang cukup memberikan dampak adiksi terhadap smartphone adalah self-esteem, dikarenakan self-esteem mempunyai peranan penting dalam menentukan perilaku individu dan bagaimana seseorang dapat menghargai dirinya sendiri. Self-esteem yang tinggi akan menimbulkan kepercayaan diri yang kuat, merasa dirinya berguna dan mampu memberikan perilaku yang sesuai dengan situasi sehingga tidak ada rasa bersalah terhadap perilaku yang dimunculkan. Jika individu memiliki self-esteem yang rendah maka individu merasa tidak percaya diri terhadap perilaku yang telah dilakukannya, merasa tidak tenang dengan perilaku yang dimunculkan dan gelisah. (Michinton,J. 1993), sehingga individu yang memiliki self-esteem yang rendah cenderung sulit untuk menampilkan dan mengekspresikan perilakunya terhadap orang lain dan cenderung menampilkannya dengan cara menggunakan perantara salah satunya dengan menggunakan smartphone agar mereka tetap bisa menjalin komunikasi dan mengekspresikan perasaan mereka tanpa ada rasa bersalah terhadap orang lain.

Hal ini sejalan dengan pernyataan dari Bianchi dan Phillips (dalam Phillips,J,2006) yang menemukan bahwa orang-orang yang memiliki masalah atau mengalami adiksi terhadap smartphone, lebih cenderung berusia muda, extrovert, dan memiliki harga diri yang rendah. Namun berbeda dengan yang dikemukakan Greenberg (1999) bahwa harga diri adalah berhubungan positif dengan olah raga tetapi tidak terkait dengan adiksi lainnya seperti internet, smartphone, rokok, alcohol, televisi,dll.

Perilaku seseorang mempengaruhi dan dipengaruhi oleh tingkat self-esteem yang dimilikinya, apakah self-esteem orang tersebut tinggi atau rendah. Selfesteem mempunyai peranan penting dalam menentukan perilaku individu. Dimana self-esteem merupakan penilaian yang diberikan pada dirinya sendiri, atau penilaian diri individu sebagai manusia berdasarkan bagaimana ia menerima atau menolak perilaku dan dirinya sendiri. (Michinton,1993). Dari uraian diatas, dapat diasumsikan bahwa individu yang memiliki Self-esteem tinggi akan mudah berkomunikasi dengan orang lain baik di social media atau melalui smartphone maupun didunia nyata, sedang individu yang memiliki Self-esteem rendah dikhawatirkan akan memiliki kesulitan berkomunikasi interpersonal dengan orang lain, baik disosial media maupun didunia nyata.

Terkait pembahasan dalam penelitian ini, penulis berminat meneliti penggunaan internet melalui smartphone dikalangan remaja khususnya di janjang SMA kelas X, XI, dan XII. Selama periode masa remaja, orang tua adalah bagian yang terdekat dan memegang peranan penting dalam memberikan pengawasan dan pengelolaan waktu luang anak. Hasil temuan dari Technological Educational Institute (TEI) di Heraklion menemukan bahwa parenting style menentukan resiko adiksi internet pada anak. Studi penelitian tersebut berfocus pada lebih dari 700 anak dewasa muda, yang hampir semuanya berusia sekitar 20 tahun, mereka mengisi kuesioner selama pelajaran dikelas. Responden menjawab pertanyaan mengenai rasa kesepian, kesedihan, kecemasan, dan tentang pemakaian smartphone. Dari hasil penelitian tersebut diketahui bahwa dewasa muda yang memiliki orang tua yang tegas, unaffected dan menuntut, lebih mungkin memiliki anak yang adiksi terhadap smartphone. Sebaliknya, peneliti menjelaskan parenting yang hangat, caring dan orang tua yang bersifat melindungi berasosiasi dengan rendahnya resiko adiksi smartphone. Penelitian ini juga menyebutkan bahwa parenting yang salah dapat mendidik anak menjadi anak yang pemurung, mengalami kesulitan dalam pertemanan, dan beberapa trait kepribadian dapat meningkatkan resiko adiksi smartphone (dailymail.co.uk,2014).

Parenting merupakan kegiatan kompleks yang mencakup perilaku spesifik tertentu yang bekerja secara sendiri-sendiri atau terpisah dan bersamaan untuk mempengaruhi perilaku anak (Darling,1999). Baumrind (1966) membedakan parenting style menjadi 3 jenis, yaitu: (1) Authoritarian; Orang tua cenderung membentuk, mengontrol dan mengevaluasi perilaku dan sikap anak dengan memberikan standart, biasanya dengan standart yang absolute. (2) Authoritative, orang tua cenderung mengarahkan aktivitas anak tetapi dengan alasan yang rasional, dan bertindak sesuai dengan masalah yang dihadapi. (3) Permisive; Orang tua cenderung berperilaku dengan tidak menghukum, menerima dan mendorong anak untuk bersikap otonomi, mendidik anak berdasarkan logika dan memberi kebebasan pada anak untuk menentukan tingkah laku dan kegiatannya.

Parenting style adalah salah satu faktor yang ada pada masa anak-anak dan remaja yang dapat menentukan perilaku seseorang dimasa mendatang. Remaja yang berada dalam lingkungan keluarga yang kurang hangat dan kurang dukungan, akan termotivasi untuk mencari alternative lain, yaitu Samrtphone. Hasil penelitian barubaru ini oleh Moazedian,dkk (2014) mengindikasikan bahwa ada pengaruh yang signifikan parenting style authoritative dengan tingginya level pada permasalahan 
penggunaan samrtphone. Selain itu jenis parenting style permissive dan authoritative juga berkolerasi dengan rendahnya masalah penggunaan internet. Hal ini didukung oleh penelitian bahwa anak dengan jenis parenting style authoritative membuat anak menjadi lebih mau menerima pengaruh orang tua dikarenakan orang tua tidak memaksakan keinginan mereka kepada anaknya tetapi justru memberikan mereka alasan dan penjelasan untuk mengadopsi perilaku dan nilai-nilai tertentu dari orang tua mereka (Golmohammadian dkk, 2010, Sapieja dkk, 2011). Hasil ini juga mendukung penemuan bahwa anak dengan jenis parenting style authoritative kemungkinan kecil untuk mengkonsumsi atau menggunakan barang-barang terlarang, seperti: tembakau, alqohol, dan obat-obat terlarang lainnya dibanding dengan anak dari orang tua yang lalai (Adalbjarmardottir \& Haftsteinsson, 2001).

Berdasarkan beberapa hasil penelitian terdapat beberapa perbedaan jenis parenting style yang berpengaruh terhadap adiksi smartphone. Misalnya saja, Moezedian (2014) menemukan bahwa authoritarian berpengaruh hanya pada highest level of internet addiction, sedangkan authoritative dan permissive berhubungan hanya dengan low level of internet addiction. Sedangkan Aunola dkk (2000) mendapati bahwa parenting style permissive yang justru berpengaruh paling dominan terhadap adiksi smartphone, sedangkan authoritarian berada pada posisi paling akhir dalam mempengaruhi adiksi smartphone. Bahkan Eastin (dalam Valcke 2010) mendapati bahwa parenting style tidak berpengaruh terhadap adiksi smartphone. Dengan demikian, masih terdapat perbedaan hasil penelitian mengenai pengaruh parenting style terhadap adiksi internet. Oleh karena itu, penulis ingin mengetahui lebih lanjut pengaruh parenting style terhadap adiksi internet khususnya dikalangan remaja.

Selain itu, menurut Leung (dalam casey, B.M, 2012) ada beberapa faktor yang menyebabkan terjadinya adiksi smartphone, yaitu: adanya kesenjangan waktu sehingga bosan, mencari sensasi dan self-esteem. Namun, menurut literature psikologi lainnya loneliness dan shyness merupakan predictor seseorang mengalami adiksi smartphone pada murid-murid di China (Casey, B.M, 2012)

Menurut Park (dalam Casey,B.M, 2012) adalah rasa kesepian yang secara positif berkolerasi dengan adiksi smartphone, dikarenakan orang yang kesepian cenderung menggunakan smartphone lebih banyak. Begitu pula penelitian yang dilakukan oleh Afdal (2013) bahwa loneliness mempunyai korelasi yang signifikan terhadap adiksi smartphone dimana internet juga merupakan bagian dari adiksi smartphone. Kesepian muncul karena tidak adanya hubungan social yang mampu memuaskan kebutuhan akan kedekatan dan rasa memiliki. Reid, D.J (2007) mengatakan bagaimana ternyata kontak social tidak hanya melindungi seseorang terhadap kesepian, bahkan dapat memperbaikinya. Karena itu kesepian mungkin timbul sebagai akibat kurangnya hubungan yang lebih intim dari pada kurangnya hubungan dengan diri sendiri. Sementara pertukaran sms (sent message system), chating, dan lainnya dengan aplikasi smartphone mungkin dapat memperbaiki rasa kesepian. Orang-orang yang kesepian cenderung menggunakan smartphone mereka untuk mengasosiasikan kebutuhan sosialisasi mereka dengan berbagai aplikasi komunikasi internet yang ada pada smartphone. (Reid,D.J. 2007).

Berdasarkan uraian pada latar belakang yang telah penulis uraikan seperti tersebut diatas, berangkat dari faktor-faktor yang mempengaruhi terjadinya adiksi remaja terhadap internet melalui smartphone, maka rumusan masalah yang akan diteliti ingin melihat sejauhmana Pengaruh Self Control, Self-Esteem, Parenting Style, dan Loneliness terhadap adiksi internet melalui Smartphone

\section{METODE}

Dalam penelitian ini menggunakan jenis penelitian kuantitatif. Tempat penelitian di SMA X BSD. Jumlah populasi diambil dari siswa kelas X,XI, dan XII yang berusia antara 16-18 tahun sebanyak 140 orang. Untuk sampel berjumlah 103 orang siswa. Sampel yang dipilih berdasarkan teknik proporsional random sampling dengan menggunakan table morgan. Pengumpulan data dilakukan dengan menggunakan metode skala. Selain skala, penulis juga menggunakan studi lapangan, kasus dan wawancara sederhana kepada beberapa siswa sebagai data pendukung. Dalam penelitian ini metode skala yang digunakan adalah skala adiksi internet, self-control, self-esteem, permissive parenting style, dan loneliness yang peneliti buat secara mandiri. Adapun aspek-aspek yang diukur dalam penelitian ini adalah Untuk skala adiksi internet antara lain: Salience, Tolerance, Mood modification, Relaps, With drawal, Conflict (Griffiths: 2002). Untuk skala Self-control aspeknya adalah Behaviour control, Cognitif control dan Decisional Control (Averil:1973). Untuk skala Self esteem aspeknya adalah Perasaan terhadap diri sendiri, Perasaan tentang hidup, dan hubungan dengan orang lain (Minchinton:1993). Untuk skala Permissive Parenting Style aspeknya adalah Parenting Permissive Indefferent dan Parenting Permissive-Indulgent Maccoby: 2005). Dan terakhir untuk skala Loneliness aspek yang diukur adalah Emosional Isolation Loneliness dan Social Isolation Loneliness (Santrock:2003). 
Uji validitas item menggunakan teknik Korelasi Product Moment Karl Pearson dengan program SPSS versi 17.0 for Windows, sementara untuk uji reliabilitas menggunakan teknik formula cronbach's alpha dengan SPSS versi 17 for windows dengan taraf signifikansi 0.05 . Hasil uji coba instrument untuk skala adiksi internet terdapat 50 item yang valid dan 13 item yang gugur. Untuk

Tabel 4.3

Self-esteem dan Adiksi Internet dengan Self-control Sebagai mediator

\begin{tabular}{llclll}
\multicolumn{7}{c}{ Sebagai mediator } \\
\hline & Input: & & Test statistic: & Std. Error: & $p$-value: \\
\hline$a$ & -0.887 & Sobel test: & 2.53519693 & 0.12840383 & 0.01123841 \\
$b$ & -0.367 & Aroian test: & 2.52334449 & 0.12900696 & 0.01162445 \\
$S_{\mathrm{a}}$ & 0.089 & Goodman test: & 2.54721798 & 0.12779786 & 0.01085856 \\
$S_{\mathrm{b}}$ & 0.140 & & & & \\
\hline
\end{tabular}

skala Self-control terdapat 28 item yang valid dan 5 item yang gugur. Untuk skala Self-esteem terdapat 50 item yang valid dan 11 item yang gugur. Untuk skala Permissive Parenting Style terdapat 30 item yang valid dan 6 item yang gugur. Untuk skala Lonelinness terdapat 20 item yang valid dan 2 item yang gugur.

Hasil uji reliabilitas item pada penelitian ini menggunakan perhitungan Cronbach's alpha didapat koefisien reliabilitas untuk skala adiksi internet sebesar 0,942; skala Self-control sebesar 0,913; skala Self-esteem sebesar 0,948; skala Parenting Permissive Style sebesar 0,929 dan skala Loneliness sebesar 0,793. Berdasarkan kaidah Gulford dan Frucher (dalam Arikunto, 2002) bahwa nilai antara 0,7 - 0,9 dikatakan reliable. Sedang metode analisis data pada penelitian ini adalah menggunakan teknikmulti regresi.

\section{HASIL DAN PEMBAHASAN}

Analisis Deskriptif Variabel Self Contol, Self Esteem, Parenting Style, Lonelinness, Adiksi Smartphone

Untuk melihat bagaimana gambaran dari masingmasing variable akan dijelaskan melalui table 4.1 , berikut penjelasannya :

\begin{tabular}{llllll}
\multicolumn{6}{c}{ Tabel 4.1 Statistik Deskriptif Variabel } \\
\hline & Self-esteem & $\begin{array}{l}\text { Permissive } \\
\text { parenting style }\end{array}$ & Loneliness & $\begin{array}{l}\text { Adiksi } \\
\text { Internet }\end{array}$ & $\begin{array}{l}\text { Self- } \\
\text { control }\end{array}$ \\
\hline Mean & 133.1456 & 77.0000 & 49.6019 & 137.4466 & 76.1456 \\
Mode & 128.00 & 74.00 & 51.00 & 154.00 & 81.00 \\
Std. Deviation & 16.82459 & 8.86168 & 7.00747 & 21.85636 & 10.69030 \\
Variance & 283.067 & 78.529 & 49.105 & 477.701 & 114.283 \\
Minimum & 75.00 & 60.00 & 35.00 & 85.00 & 47.00 \\
Maximum & 166.00 & 113.00 & 74.00 & 180.00 & 95.00 \\
& & & & & \\
\hline
\end{tabular}

Dari gambaran table 4.1 diatas, dapat dijelaskan bahwa variable self-esteem memiliki nilai mean 133,1456; median 134; modus 128; standar deviasi 16,824 dan varians sebesar 283,067. Variable permissive parenting style memiliki nilai mean 77; median 76; modus 74; standar deviasi 8,862 dan varians sebesar 78,529. Variable loneliness memiliki nilai mean 49,6019; median 49; modus 51; standar deviasi 7,007 dan varians sebesar 49,105. Variable Adiksi memiliki nilai mean 133,1456; median 134; modus 128; standar deviasi
16,824 dan varians sebesar 283,067. Hal tersebut menegaskan adanya pengaruh antara self-esteem, permissive parenting style dan loneliness terhadap adiksi internet.

Pengaruh self-esteem terhadap adiksi internet menggunakan smartphone dengan self-control sebagai mediator. Tabel 4.3 akan menjelaskan pengaruh self

esteem terhadap adiksi internet dengan self-control

Dari hasil uji Sobel Test diatas diperoleh nilai z sebesar 2,535. Karena nilai z yang diperoleh sebesar 2,535 > 1,98 maka signifikan. Hal ini membuktikan bahwa selfcontrol mampu memediasi pengaruh self-esteem terhadap adiksi internet. Dengan demikian dapat dikatakan bahwa self-control merupakan mediator yang dapat menguatkan atau meningkatkan pengaruh self-esteem terhadap adiksi internet.

Pengaruh permissive parenting style terhadap adiksi internet menggunakan smartphone dengan self-control sebagai mediator

Tabel 4.5 Permissive porenting style dengan self-control sebagai mediator dengan Adiksi Internet

\begin{tabular}{llclll}
\hline & Input: & & Test statistic: & Std. Error: & $p$-value: \\
\hline$a$ & 1.641 & Sobel test: & -2.64087039 & 0.24420471 & 0.00826933 \\
$b$ & -0.393 & Aroian test: & -2.62757659 & 0.24544023 & 0.00859955 \\
$S_{a}$ & 0.172 & Goodman test: & -2.65436802 & 0.24296292 & 0.00794571 \\
$S_{b}$ & 0.143 & & & & \\
\hline
\end{tabular}

Dari hasil uji Sobel Test diatas diperoleh nilai $\mathrm{z}$ sebesar -2,640. Karena nilai z yang diperoleh sebesar 2,640 > 1,98 maka signifikan. Hal ini membuktikan bahwa self-control mampu memediasi pengaruh parenting style permissive terhadap adiksi internet. Dengan demikian dapat dikatakan bahwa self-control merupakan mediator yang dapat menguatkan atau meningkatkan pengaruh permissive parenting style terhadap adiksi internet.

Pengaruh loneliness terhadap adiksi internet menggunakan smartphone dengan self-control sebagai Mediator

Tabel 4.7 akan menjelaskan pengaruh loneliness dan Self-control sebagai mediator dengan Adiksi Internet

$$
\text { Tabel } 4.7
$$

\begin{tabular}{llllll}
\multicolumn{6}{c}{ Loneliness dan Self-control sebagai mediator dengan Adiksi Internet } \\
\hline & Input: & & $\begin{array}{l}\text { Test } \\
\text { statistic: }\end{array}$ & Std. Error: & $p$-value: \\
\hline $\boldsymbol{a}$ & 2.376 & Sobel test: & -4.33314319 & 0.28293918 & 0.0000147 \\
$\boldsymbol{b}$ & -0.516 & Aroian test: & -4.32283733 & 0.28361373 & 0.0000154 \\
$\boldsymbol{S}_{\boldsymbol{a}}$ & 0.173 & Goodman test: & -4.34352312 & 0.28226303 & 0.00001402 \\
$\boldsymbol{S}_{\boldsymbol{b}}$ & 0.113 & & & & \\
\hline
\end{tabular}

Dari perhitungan koefisien korelasi diperoleh nilai $\mathrm{z}$ $=-4.333$ Karena nilai $\mathrm{z}$ yang diperoleh sebesar $-4,333>$ 
1,98 maka signifikan. Hal ini membuktikan bahwa selfcontrol mampu memediasi pengaruh loneliness terhadap adiksi internet. Dengan demikian dapat dikatakan bahwa self-control merupakan mediator yang dapat menguatkan atau meningkatkan pengaruh loneliness terhadap adiksi internet.

Pengaruh self-esteem, permissive parenting style dan loneliness terhadap adiksi internet menggunakan smartphone dengan self-control sebagai mediator

Untuk menguji hipotesis ini, teknik analisis yang digunakan adalah teknik regresi berganda menggunakan variable mediator. Hasil uji dijelaskan secara rinci pada tabel 4.10

\begin{tabular}{|c|c|c|c|c|c|c|c|c|c|}
\hline \multicolumn{10}{|c|}{$\begin{array}{c}\text { Tabel } 4.10 \\
\text { Pengaruh Self-esteem, Permissive parenting style dan Lonelines Terhadap Adiksi Internet } \\
\text { Dengan Self-control Sebagai Mediator }\end{array}$} \\
\hline \multirow[t]{2}{*}{ Model } & \multirow[t]{2}{*}{$\mathrm{R}$} & \multirow{2}{*}{$\begin{array}{l}R \\
\text { Square }\end{array}$} & \multirow{2}{*}{$\begin{array}{l}\text { Adjusted } \\
\mathrm{R} \\
\text { Square }\end{array}$} & \multirow{2}{*}{$\begin{array}{l}\text { Std. } \\
\text { Error of } \\
\text { the } \\
\text { Estimate }\end{array}$} & \multicolumn{2}{|c|}{ Change Statistics } & \multirow[b]{2}{*}{ df1 } & \multirow{2}{*}{\multicolumn{2}{|c|}{$\begin{array}{l}\text { Sig. F } \\
\text { Change }\end{array}$}} \\
\hline & & & & & $\begin{array}{l}\text { R } \\
\text { Square } \\
\text { Change }\end{array}$ & F Change & & & \\
\hline 1 & .923 & .852 & .849 & 8.48705 & .852 & 288.230 & 2 & 100 & .000 \\
\hline
\end{tabular}

Dari tabel 4.10, hasil analisis regresi diperoleh nilai $\mathrm{R}$ sebesar 0,923 dan nilai $\mathrm{R}^{2}$ (koefisien determinasi) sebesar 0.852 . Artinya $85,2 \%$ variabel adiksi internet dijelaskan oleh self-esteem, permissive parenting style dan loneliness dengan self-control sebagai mediator secara bersama-sama sebagai variabel bebasnya. Sedangkan sisanya 14,8\% variabel adiksi internet dijelaskan oleh variabel-variabel yang lain yang tidak dibahas dalam penelitian ini. Selanjutnya untuk melihat besaran sumbangan pengaruh dari masing-masing variabel dijelaskan pada tabel 4.11.

\begin{tabular}{|c|c|c|c|c|}
\hline \multicolumn{5}{|c|}{ Tabel 4.11} \\
\hline Pengaruh & $\begin{array}{c}\text { Koefisien } \\
\text { Korelasi Ganda }\end{array}$ & $\begin{array}{l}\text { Uji Keberartian } \\
\text { Modelyig. of } R\end{array}$ & $\begin{array}{l}\text { Koefisien } \\
\text { Standard }\end{array}$ & Besarnya Sumbangan \\
\hline 1. Self-esteem terhadap & $\begin{array}{l}R=-0,731 \\
R^{2}=0.535\end{array}$ & $\begin{array}{l}F=116,114 \\
p=0000\end{array}$ & $\begin{array}{l}\sum_{\text {Beta }} \\
\delta=-0,731\end{array}$ & $0,535 \times 100 \%=53,5 \%$ \\
\hline 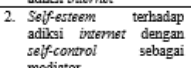 & $\begin{array}{l}\mathrm{R}=-0,6083 \\
\mathrm{R}^{2}=0,467\end{array}$ & $\begin{array}{l}F=88,517 \\
p=0,000\end{array}$ & $\begin{array}{l}\beta=0,1 \\
\beta=-0,683\end{array}$ & $0,467 \times 100 \%=46,7 \%$ \\
\hline 3. Permistshive parenting stule & $\begin{array}{l}\mathrm{R}=0,715 \\
\mathrm{R}^{2}=511\end{array}$ & $\begin{array}{l}F=105.689 \\
n=0.00\end{array}$ & $\begin{array}{l}\text { Beta } \\
\delta=0715\end{array}$ & $0,511 \times 100 \%=51,1 \%$ \\
\hline 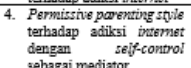 & $\begin{array}{l}\mathrm{R}=-0,683 \\
\mathrm{R}^{3}=0,467\end{array}$ & $\begin{array}{l}\mathrm{F}=8 \mathrm{~s}, 517 \\
\mathrm{p}=0,000\end{array}$ & $\begin{array}{l}\sum_{B \text { eta }} \\
\beta=-0,683\end{array}$ & $0,467 \times 100 \%=46,7 \%$ \\
\hline 5. Loneliness terhadap adiksi & $\begin{array}{l}\mathrm{R}=0,799 \\
\mathrm{R}^{2}=0.698\end{array}$ & $\begin{array}{l}F=177,783 \\
P=0,000\end{array}$ & $\begin{array}{l}\text { Beta } \\
\delta=0.799\end{array}$ & $0,638 \times 100 \%=63,8 \%$ \\
\hline 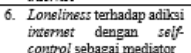 & $\begin{array}{l}\mathrm{R}=0,336 \\
\mathrm{R}^{2}=0,113\end{array}$ & $\begin{array}{l}F=12,862 \\
p=0,001\end{array}$ & $\begin{array}{l}\text { Beta } \\
\beta=0,336\end{array}$ & $0,113 \times 100 \%=11,3 \%$ \\
\hline 7. Self-control terhadap & $\begin{array}{ll}R=-0,364 \\
R^{2}=0,132\end{array}$ & $\begin{aligned} & F=15,417 \\
&=0,00\end{aligned}$ & Beta & $0,132 \times 100 \%=13,2 \%$ \\
\hline 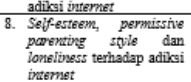 & $\begin{array}{l}\mathrm{R}^{2}=0,132 \\
\mathrm{R}=0,920 \\
\mathrm{R}^{\prime}=0,846\end{array}$ & $\begin{array}{l}p=0,000 \\
F=181,798 \\
p=0,000\end{array}$ & $\begin{array}{l}\beta=-0,364 \\
\text { Beta } \\
\beta=-0,473 \\
\beta=0,089 \\
\beta=0,547\end{array}$ & $0,846 \times 100 \%=84,6 \%$ \\
\hline 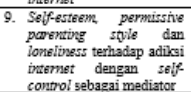 & $\begin{array}{l}\mathrm{R}=0,923 \\
\mathrm{R}^{\prime}=0,852\end{array}$ & $\begin{array}{l}F=288,230 \\
p=0,000\end{array}$ & $\begin{array}{l}\text { Beta } \\
\beta=-0,920 \\
\beta=0,664\end{array}$ & $0,852 \times 100 \%=85,2 \%$ \\
\hline
\end{tabular}

\section{PEMBAHASAN}

Hasil penelitian ini sesuai dengan pendapat yang menyatakan bahwa self-control, loneliness dan parenting style juga menjadi predictor seseorang mengalami adiksi internet (Casey,B.M, 2012), dimana adiksi internet merupakan kecanduan kondisi terikat pada suatu kebiasaan dan tidak mampu lepas dari kebiasaan itu, individu yang kurang mampu mengontrol dirinya sendiri untuk melakukan kegiatan yang disenanginya. Menurut (Leung 2012) ada beberapa faktor yang menyebabkan terjadinya adiksi internet, yaitu adanya kesenggangan waktu sehingga bosan, mencari sensasi dan self-esteem.

Mengenai kontrol diri (self-control), seseorang pecandu akan menjadi tidak mampu mengontrol dirinya untuk melakukan kegiatan yang disenangi sehingga mengabaikan hal lainnya. Kontrol diri seseorang bisa terbentuk karena adanya aturan-aturan atau hukum yang mengikat diri agar tingkah laku yang diwujudkan bisa dikendalikan. Kegagalan dalam mengendalikan diri tersebut pada akhirnya akan membawa dampak yang negatif khususnya dalam bentuk kecanduan. Banyaknya kemampuan yang dimiliki oleh internet membuat seseorang dapat dengan mudah memenuhi kebutuhannya hanya dengan "berselancar" di internet sehingga terjadilah adiksi.

Hal ini didukung dengan teori kebutuhan maslow bahwa didalam setiap individu ada dorongan untuk memenuhi kebutuhan pada tiap tingkatan. Kebutuhan yang dapat diperoleh melalui internet seperti kebutuhan rasa aman (membangun privacy individual/ kebebasan diri) serta kebutuhan akan kasih sayang (menginginkan sebuah persahabatan dan menjadi bagian dari suatu kelompok). Individu yang tahu bahwa kebutuhannya dapat terpenuhi melalui internet dan memiliki self-control yang rendah berpotensi mengalami kecanduan karena menjadi tidak mampu untuk mengatur dirinya.

Hal lain yang cukup memberikan dampak adiksi terhadap smartphone adalah self-esteem, dikarenakan selfesteem mempunyai peranan penting dalam menentukan perilaku individu dan bagaimana seseorang dapat menghargai dirinya sendiri. Self-esteem yang tinggi akan menimbulkan kepercayaan diri yang kuat, merasa dirinya berguna dan mampu memberikan perilaku yang sesuai dengan situasi sehingga tidak ada rasa bersalah terhadap perilaku yang dimunculkan. Jika individu memiliki selfesteem yang rendah maka individu merasa tidak percaya diri terhadap perilaku yang telah dilakukannya, merasa tidak tenang dengan perilaku yang dimunculkan dan gelisah. (Michinton,J. 1993), sehingga individu yang memiliki self-esteem yang rendah cenderung sulit untuk menampilkan dan mengekspresikan perilakunya terhadap orang lain dan cenderung menampilkannya dengan cara menggunakan perantara salah satunya dengan menggunakan smartphone agar mereka tetap bisa menjalin komunikasi dan mengekspresikan perasaan mereka tanpa ada rasa bersalah terhadap orang lain.

Hal ini sejalan dengan pernyataan dari Bianchi dan Phillips (dalam Phillips,J,2006) yang menemukan bahwa orang-orang yang memiliki masalah atau mengalami adiksi terhadap internet, lebih cenderung berusia muda, extrovert, dan memiliki harga diri yang rendah. Perilaku seseorang mempengaruhi dan dipengaruhi oleh tingkat self-esteem yang dimilikinya, apakah self-esteem orang tersebut tinggi atau rendah. Self-esteem mempunyai peranan penting 
dalam menentukan perilaku individu. Dimana self-esteem merupakan penilaian yang diberikan pada dirinya sendiri, atau penilaian diri individu sebagai manusia berdasarkan bagaimana menerima atau menolak perilaku dan dirinya sendiri. (Michinton,1993). Dari uraian diatas, dapat diasumsikan bahwa individu yang memiliki Self-esteem tinggi akan mudah berkomunikasi dengan orang lain baik di sosial media atau melalui smartphone maupun didunia nyata, sedang individu yang memiliki self-esteem rendah dikhawatirkan akan memiliki kesulitan berkomunikasi interpersonal dengan orang lain, baik disosial media maupun didunia nyata. individu yang memiliki self-esteem tinggi akan menumbuhkan rasa berharga, berfikiran positif, memiliki harapan dan semangat yang positif, tujuan-tujuan positif, dan dapat menghargai diri sendiri dan orang lain. Seperti yang dikemukakan oleh Maslow (dalam Goble, 1998), bahwa setiap orang memiliki dua kategori kebutuhan akan penghargaan yaitu harga diri dan penghargaan dari orang lain. Jika seseorang yang memiliki harga diri yang tinggi dan menjaga diri agar orang lain bisa memberi penghargaan yang baik untuk dirinya maka individu akan berusaha untuk menjaga citra diri, sikap dan perilakunya agar tetap berada pada hal-hal positif, termasuk kemampuan mengontrol diri dari hal-hal yang akan merusak citra diri, baik bagi dirinya sendiri maupun dihadapan orang lain. Atas asumsi tersebut dapatlah diambil kesimpulan bahwa self-esteem mempengaruhi selfcontrol seseorang. Terkait penelitian ini, dapat dikatakan bahwa self-esteem dapat mempengaruhi self-control seseorang dalam mengontrol penggunaan internet seharihari yang akan menentukan apakah individu sudah masuk kategori adiksi internet atau tidak. Asumsi tersebut diatas didukung oleh pendapat Minchinton (1993) yang menyatakan bahwa seseorang yang memiliki self-esteem yang tinggi akan mampu memegang kendali atas diri sendiri atau kontrol diri (self-control).

Terkait dengan parenting style, orang tua yang tegas, unaffected dan menuntut, lebih mungkin memiliki anak yang adiksi terhadap internet menggunakan smartphone Sebaliknya, parenting yang hangat, caring dan orang tua yang bersifat melindungi berasosiasi dengan rendahnya resiko adiksi smartphone. Penelitian ini juga menyebutkan bahwa parenting yang salah dapat mendidik anak menjadi anak yang pemurung, mengalami kesulitan dalam pertemanan, dan beberapa trait kepribadian dapat meningkatkan resiko adiksi internet menggunakan smartphone. Baumrind (1971) menyebutkan bahwa permissive parenting style adalah gaya pengasuhan orang tua yang memiliki karakteristik rendahnya tuntutan namun sangat responsive. Orang tua terlalu permisif terhadap kebutuhan anak namun tidak memberikan struktur dan batasan - batasan yang tepat bagi anak-anak mereka.
Maccoby dan Martin (dalam Marini dan Andriani, 2005) menyatakan Parenting style permissive memanjakan (Permissive Indulgent Pattern) mengandung undemanding dan responsif. Dicirikan dengan orang tua yang terlalu membebaskan anak dalam segala hal tanpa adanya tuntutan maupun kontrol. Anak dibolehkan untuk melakukan apa saja yang diinginkannya. Orang tua permisif memanjakan ini biasanya bersikap hangat, bersifat ngemong, dan responsif, tetapi mereka menggunakan sedikit sekali struktur dan bimbingan. Karena orang tua dengan tipe ini cenderung mempercayai bahwa ekspresi bebas dari keinginan hati dan harapan sangatlah penting bagi perkembangan psikologis. Pola asuh ini berkaitan dengan ketidak cakapan sosial anak, terutama kurangnya pengendalian diri atau kontrol diri (self-control)

Parenting style adalah salah satu faktor yang ada pada masa anak-anak dan remaja yang dapat menentukan perilaku seseorang dimasa mendatang. Remaja yang berada dalam lingkungan keluarga yang kurang hangat dan kurang dukungan, akan termotivasi untuk mencari alternative lain, yaitu internet menggunakan smartphone. Sesuai deengan penelitian yang dilakukan oleh Moazedian,dkk (2014) mengindikasikan bahwa ada pengaruh yang signifikan parenting style authoritative dengan tingginya level pada permasalahan penggunaan internet smartphone. Selain itu jenis permissive parenting style dan authoritative juga berkolerasi dengan masalah penggunaan internet. Berdasarkan beberapa hasil penelitian terdapat beberapa perbedaan jenis parenting style yang berpengaruh terhadap adiksi smartphone. Misalnya saja, Moezedian (2014) menemukan bahwa parenting style permissive yang justru berpengaruh paling dominan terhadap adiksi smartphone.

Selain itu, Menurut Park (dalam Casey,B.M, 2012) adalah rasa kesepian yang secara positif berkolerasi dengan adiksi internet menggunakan smartphone, dikarenakan orang yang kesepian cenderung menggunakan smartphone lebih banyak. Begitu pula penelitian yang dilakukan oleh Afdal (2013) bahwa loneliness mempunyai korelasi yang signifikan terhadap adiksi internet menggunakan smartphone. Kesepian muncul karena tidak adanya hubungan sosial yang mampu memuaskan kebutuhan akan kedekatan dan rasa memiliki. Reid, D.J (2007) mengatakan bagaimana ternyata kontak sosial tidak hanya melindungi seseorang terhadap kesepian, bahkan dapat memperbaikinya. Karena itu kesepian mungkin timbul sebagai akibat kurangnya hubungan yang lebih intim dari pada kurangnya hubungan dengan diri sendiri. Sementara pertukaran sms (sent message system), chating, dan lainnya dengan aplikasi smartphone mungkin dapat memperbaiki rasa kesepian. Orang-orang yang kesepian cenderung menggunakan smartphone mereka untuk mengasosiasikan kebutuhan sosialisasi mereka dengan berbagai aplikasi 
komunikasi internet yang ada pada smartphone. (Reid,D.J. 2007). self-control berpengaruh pada individu yang mengalami kesepian terkait mengakses internet menggunakan smartphone. Hal tersebut didukung oleh penelitian Vitasari (2016), yang menyatakan ada hubungan negatif dan signifikan antara kontrol diri dengan kesepian. Dan didukung pula dengan pendapat dari Horowitz, French, dan Anderson (1982), mengkategorisasikan tiga tipe atribut utama orang yang kesepian. Kategori pertama termasuk perasaan dan pikiran yang menjadi berbeda, terisolasi, dan berpisah dengan orang lain. Kedua, mencakup perasaan negatif dari depresi, kesedihanm marah, ketidak mampuan mengontrol perasaan dan emosi, dan bahkan paranoia. Yang terakhir ialah sesuatu yang melibatkan tidakan, seperti menghindari kontak sosial atau bekerja dengan waktu yang lama, atau menggunakan smartphone berbasis internet sebagai pelarian tidak perduli seberapa sering hingga kehilangan kemampuan mengontrol diri terhadap internet.

\section{PENUTUP}

\section{Simpulan}

Dari hasil penelitian maka dapat dihasilkan kesimpulan bahwa : Ada pengaruh yang signifikan antara Self-esteem terhadap Adiksi internet menggunakan smartphone dengan self-control sebagai mediator di SMA ISLAM X . Ada pengaruh antara Permissive Parenting Style dengan Adiksi internet menggunakan smartphone dengan Self-Control sebagai mediator di SMA ISLAM X . Ada pengaruh antara Loneliness terhadap adiksi internet menggunakan smartphone dengan self-control sebagai mediator di SMA ISLAM X. Ada pengaruh antara selfesteem, permissive parenting style dan loneliness terhadap adiksi internet menggunakan smartphone dengan selfcontrol sebagai mediator di SMA ISLAM X.

\section{DAFTAR PUSTAKA}

Adalbjarnardottir,S. \& Hafsteinsson, L.G. (2001). Adolescents' perceived parenting style and their substance use: concurrent and longitudinal analyses. Journal of research on Adolescence. 11:401-23.

Baumrind,D (1991). The influence of parenting style on adolescent competence and substance use. The journal of Early Adolescence, 11, 56-95.

Baumrind,D.(2005). Pattern of parental authority and adolescent autonomy. New Directions for child and adolescent development,no.108.
Baumeister,R,F., \& Vohs,K.D (2007). Handbook of selfregulation: research, Theory. and applications ( $2^{\text {nd }}$ ed). New York. The Guilford Press.

Chaplin (2008) Peran Internet dalam dunia Pendididkan. Diambil tanggal 10 agustus 2009 dari Http// Chaplinblogdetik.com/2008/08/02/peraninternet-dalam-dunia-pendidikan.

Cooper,A (2002). Sex \& The Internet : A guide book for clinicians. New York: Brunner Routledge.

Darling,N (1999). Parenting style and its correlats. EDOPS-99-3. Diunduh tanggal 28 Januari 2014 dari http://ecap.cre.illionois.edu/ecearchiev/digests/19 99/darlin99.pdf.

Finkel,E.,J., \& Campbell,W.K. (2001). Self-control and accommodation in close relationship. An interdependence analysis. Journal of Personality and Social Psychology, 81, 265-277.

Gailliot,M.T., Baumeister,R.F., De Wall,C.N., Maner, J.K, Plant, E.A., \& Tice, D.M., et al (2007). Selfcontrol relies on glucose as a limited energy source: willpower is more than a metaphor. Journal of Personality and Social Psychology,92, 325-336

Greenfield.D. (1999). The addictive Properties of Internet Usage. Dalam Young.K.S. and Abreu. C.N de (eds.) (2011). Internet addiction: A Hand book and Guide to evaluation and Treatment. Hoboken, NJ: John willey \& Sons.

Iskandar,2008. Metodologi Penelitian Pendidikan dan sosial (kualitatif dan Kuantitatif) Jakarta: Gaung Persada Press.

Kartono, kartini. 1988. Psikologi Remaja. Bandung: PT. Rosda Karya.

Leemmens, J.S., Valkenburg.P.M, Petter.J.(2009) Development and Validation of game addiction scale for adolescent. Media Psychology.12.77-95. 001:10.1080/15213260802669458

Niemz,K, Ghriffiths,M \& Banyard,P(2005). Prevalence of pathological internet use among university student and correlations with self-esteem, the 
general health questionnaire $(G H Q)$, and disinhibition. Cyber Psychology \& behavior,8(6), $562-570$

Novianty, D. D., Sriati, A., \& Yamin, A. (2019). GAMBARAN PENGGUNAAN DAN TINGKAT KECANDUAN INTERNET PADA $\begin{array}{llll}\text { SISWA-SISWI SMA } & \mathrm{X} & \text { DI }\end{array}$ JATINANGOR. Jurnal Keperawatan

Komprehensif (Comprehensive Nursing Journal), 5(2), 76-87.

Minchinton, T. E., \& Scheibling, R. E. (1993). Variations in sampling procedure and frequency affect estimates of recruitment of barnacles. Marine Ecology Progress Series, 83-88.

Papalia,Old, Fielman. (2009). Human development: perkembangan manusia. Edisi 10 buku 2. Jakarta: Salemba Humanika.

Powell,J. (2004) Self-esteem. United State: Smart apple Media

Ras Foundation, 2017, Instagram

Sarafino,E.P (1998) Health Psychology: Biopsychosocial Interaction. Second Edition. New York: John Willey \& Sons

Vohs,K.D., et al. (2007). Making Choice Impairs Subsequent Self-Control: A limited-Resource Account of Decision Making, Regulation, and Active Initiative.J Pers Soc Psychol, Vol.94.No.5,app 883-98

Weiss,E.1982. Rickttsiales.In Parker,S.P, Synopsis and dessification of living oraganism, Vol.1. Mc Grow-Hill.New York: 40-41

Young, K.S. (1996). Internet addiction: the emergence of a new clinical disorder. CyberPsychology and Behaviour,I(3), 237-244.

Zahrani,Nadida, (2014) Pengaruh self-esteem, loneliness dan factor demografi terhadap kecenderungan adiksi Smartphone. Skripsi. Fakultas psikologi UIN Syarif Hidayatullah. Tidak diterbitkan. 